\title{
MANOVA with Summary Statistics: A STATA Program
}

\author{
Nadeem Shafique Butt \\ Department of Social and Preventive Pediatrics, KEMU \\ Lahore \\ Muhammad Qaiser Shahbaz \\ Department of Mathematics \\ COMSATS Institute of Information Technology, Lahore, Pakistan \\ Shahid Kamal \\ College of Statistical and Actuarial Sciences \\ University of the Punjab, Lahore
}

\begin{abstract}
Almost all available statistical packages are capable of performing Multivariate Analysis of Variance (MANOVA) from raw data. Some of statistical packages have capability to perform independent sample t-test, ANOVA and some other tests of significance on summary data, but you come across not single software that has the capability to perform MANOVA directly on summary data. A STATA programme has been written to perform Multivariate ANOVA on summary data. The programme computes available statistics for Multivariate ANOVA (i.e Willk's Lembda, Lawley's-Hotelling trace, Pillae's trace and Roy's largest root). The programme is also capable to perform Box-M test for testing equality of covariance matrices on summary data. Example has been given by using the programme on summary data to perform Multivariate ANOVA.
\end{abstract}

Keywords: ANOVA, MANOVA, Summary data.

\section{Introduction}

Multivariate ANOVA (MANOVA) has been widely used for comparison of several factors when information on several variables has been collected. The simplest case is One Way MANOVA where levels of single factors are compared on the basis of information of several variables. One simple use of One Way MANOVA is to test the equality of mean vectors of several Multivariate Normal populations having common covariance matrix.

Most of the statistical packages are designed to conduct several test of significance when raw data is available, but in many practical situations only summary information is available (e.g. $n$ 's, $\bar{X}$ 's, $S . D^{\prime} s, \ldots$. . ) from some report/research paper etc. Now some statistical package providers start realizing this situation and they have included some procedures in their software to perform some test of significance from summary data (e.g. Chi-Square, t-tests, ANOVA etc). David A. Larson (1992) describes a method to generate surrogate data from the summary statistics that can be used to perform one way ANOVA. 
According to Larson one has to generate two new columns namely $X_{j}{ }^{\prime} s$ and $X_{n}$ 's as

$$
X ' s=\bar{X} ' s_{j}+\sqrt{\frac{S_{j}^{2}}{n_{j}}} \text { and } X_{n}{ }^{\prime} s=n_{j} \bar{X}_{j}-\left(n_{j}-1\right) X_{j}{ }^{\prime} s
$$

And after some data manipulation data is ready to perform ANOVA in usual way.

Butt et al (2006) used an alternative method that can be used to perform one way, two way and higher way ANOVA by using summary measures $n_{j}, \bar{x}_{j}$ and $s_{j}$ for $j=1,2, \ldots, k$, where $n_{j}, \bar{x}_{j}$ and $s_{j}$ are, respectively, the size, mean and standard deviation of $j$-th treatment. In this paper we extend this idea for the Multivariate Analysis of Variance case and have developed a STATA programme that can be used to perform one way MANOVA on summary data.

\section{Methodology}

The Multivariate ANOVA is a natural extension of the univariate ANOVA. In this technique the observation vectors are available from the multivariate normal populations having common covariance matrices. The task is to compare the mean vectors of these multinormal populations. Extending the idea of univariate study, the multivariate ANOVA can be presented as the Multivariate Linear Model. Specifically, the one way multivariate ANOVA model is given as:

$$
\mathbf{x}_{i j}=\boldsymbol{\mu}+\boldsymbol{\tau}_{j}+\boldsymbol{\varepsilon}_{i j} ; \boldsymbol{\varepsilon}_{i j} \text { has } N_{p}(\mathbf{0} ; \boldsymbol{\Sigma}) \text { and }\left\{\begin{array}{l}
j=1,2, \ldots \ldots, k \\
i=1,2, \ldots \ldots, n_{j}
\end{array}\right.
$$

The hypothesis of interest in the fixed effect one way MANOVA model is generally given as:

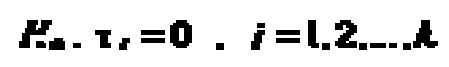

Another simple use of the one way MANOVA model is to test the hypothesis:

$$
H_{0}: \boldsymbol{\mu}_{1}=\boldsymbol{\mu}_{2}=\cdots \cdots=\boldsymbol{\mu}_{k}
$$

when independent random samples are available from $N_{p}\left(\boldsymbol{\mu}_{j} ; \boldsymbol{\Sigma}\right)$.

Several test statistics are available in literature that enables us to test the hypothesis given in (2.2) and (2.3). The most popular of these statistics is the one given by Willks (1932). The statistic given by Willks (1932) is the ratio of two generalized variances and is given as:

$$
F_{0}=\left[\frac{m s-p(k-1) / 2+1}{p(k-1)}\right] \cdot \frac{1-\Lambda^{1 / s}}{\Lambda^{1 / s}}
$$


with $\quad \Lambda=\frac{|\mathbf{W}|}{|\mathbf{B}+\mathbf{W}|} ; \mathbf{W}=\sum_{j=1}^{k}\left(n_{j}-1\right) \mathbf{S}_{j} ; \mathbf{B}=\sum_{j=1}^{k} n_{j} \overline{\mathbf{x}}_{j} \overline{\mathbf{x}}_{j}^{\prime}-n \overline{\mathbf{x x}}^{\prime}$

The quantities $\overline{\mathbf{x}}_{j}$ and $\mathbf{S}_{j}$ are the mean vector and covariance matrix for $j-$ th group and $\overline{\mathbf{x}}$ is the combined mean. The statistic given in (2.4) has an exact $F_{p(k-1) ; m s-p(k-1) / 2+1}$ where:

$$
m=(n-1)-(p+k) / 2 ; S^{2}=\frac{p^{2}(k-1)^{2}-4}{p^{2}+(k-1)^{2}-5}
$$

Another statistic proposed by Hotelling (1951) is based upon the trace of $\mathbf{T}^{-1} \mathbf{B}$ and is given as:

$$
V=\operatorname{tr}\left(\mathbf{T}^{-1} \mathbf{B}\right) ; F_{1}=\frac{[(n-k-p-1)+a+1] V}{[(|k-1-p|-1)+a+1](a-V)} ; a=\min (k-1, p)
$$

The expression given in (2.7) has: $F_{[(|k-1-p|-1)+a+1] ;[(n-k-p-1)+a+1]}$

Pallie's trace (1955) has proposed yet another statistic based upon the trace of $\mathbf{W}^{-1} \mathbf{B}$. This statistic is given as:

$$
U=\operatorname{tr}\left(\mathbf{W}^{-1} \mathbf{B}\right) ; \mathrm{F}_{2}=\frac{2 U[a(n-k-p-1) / 2+1]}{a^{2}[(2|k-p-1|-1) / 2+a+1]}
$$

The expression given in (2.8) has: $F_{a[|k-1-p|+a] ; a(n-k-p-1)+2}$

Roy (1953) built his statistic on the largest root of $\mathbf{W}^{-1} \mathbf{B}$. His statistic is given as:

$$
\begin{aligned}
& R=\max \left(\lambda_{i}\right) ; \quad \mathrm{F}_{3}=\frac{R(n-b-1)}{b} ; b=\max (k-1, p) \\
& \lambda_{i} \text { are eigen values of } \mathbf{W}^{-1} \mathbf{B} ;
\end{aligned}
$$

The expression given in (2.9) has : $F_{b ; n-b-1}$

The programme also performs the Box (1949) test for equality of covariance matrices by using the statistic:

$$
B_{0}=M C ; M=(n-k) \ln |\mathbf{S}|-\sum_{j=1}^{k}\left(n_{j}-1\right) \mathbf{S}_{j} ; \mathbf{S}=(n-k)^{-1} \mathbf{W}
$$

and $\quad C=1-\frac{2 p^{2}+3 p-1}{6(k-1)(p+1)}\left[\sum_{j=1}^{k} \frac{1}{n_{j}-1}-\frac{1}{n-k}\right]$

In the following section we have given the programme and a live example is given in section 4 of the paper. 


\section{STATA Program}

In this section we have given a Stata Mata program named "manovai.ado" that can be used to perform the MANOVA on summary data. The program "manovai.ado" requires four arguments as input, variable of group identification, variable of sample sizes, variable of mean vectors and variables of variancecovariance matrices respectively.

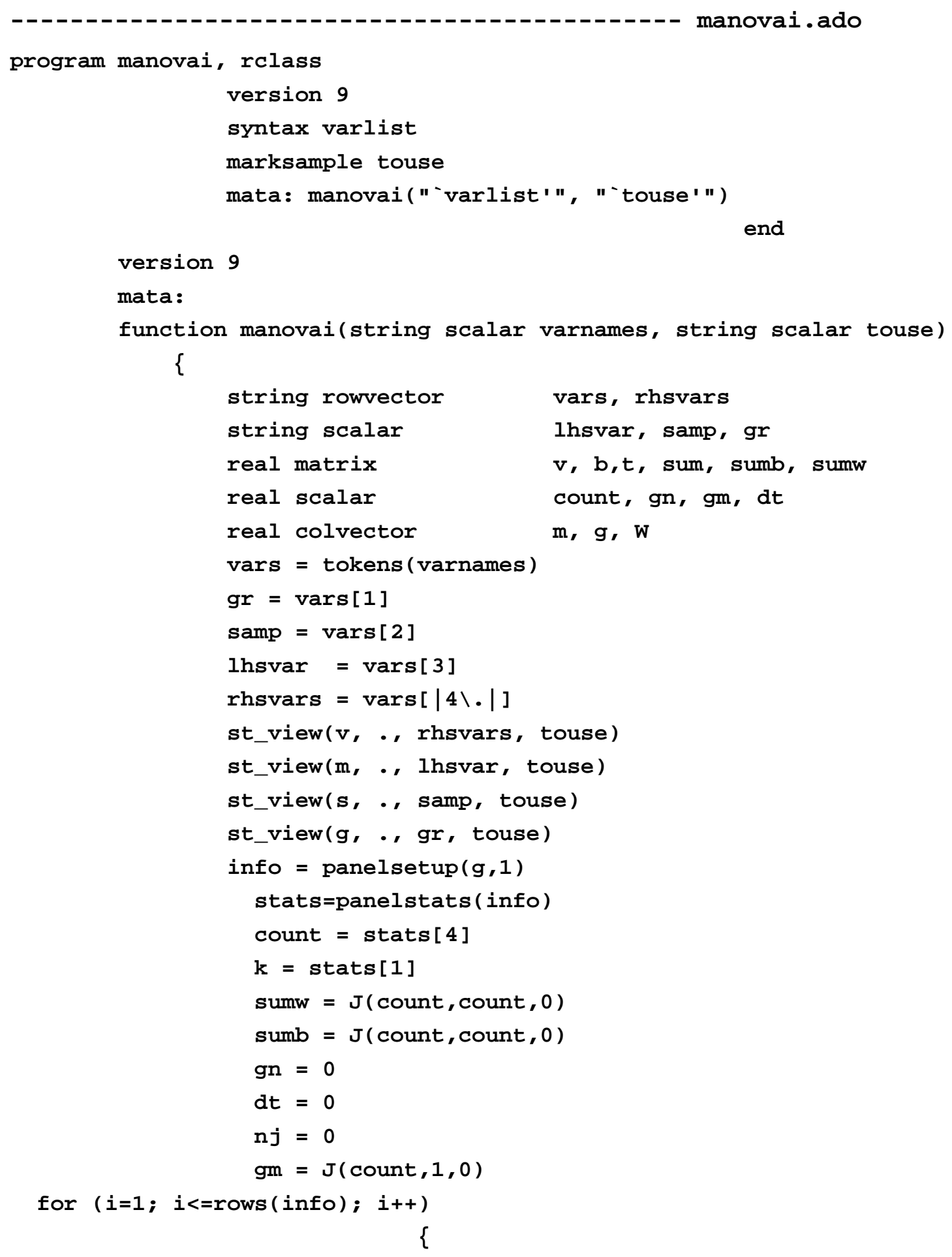




$$
\begin{aligned}
& v_{-} i=\text { panelsubmatrix }(v, i, \text { info }) \\
& m \_i=\text { panelsubmatrix }(m, i, i n f o) \\
& n \_i=\operatorname{panelsubmatrix}(s, i, i n f o) \\
& \mathbf{n}=\operatorname{mean}\left(\mathbf{n} \_\mathbf{i}\right) \\
& \operatorname{det}=\left(\log \left(\operatorname{det}\left(v_{-} i\right)\right)\right) *(n-1) \\
& w_{-} i=(n-1) * v \_i \\
& \text { b_i=n*m_i* }\left(m \_i\right) ' \\
& \text { gn }=\text { gn }+\mathbf{n} \\
& g m=\left(\left(g m+m \_i^{*} n\right)\right) \\
& \text { sumw }=\text { sumw }+w_{-} i \\
& \text { sumb }=\text { sumb }+b \_i \\
& \mathrm{dt}=\mathrm{dt}+\mathrm{det} \\
& n j=n j+1 /(n-1)
\end{aligned}
$$

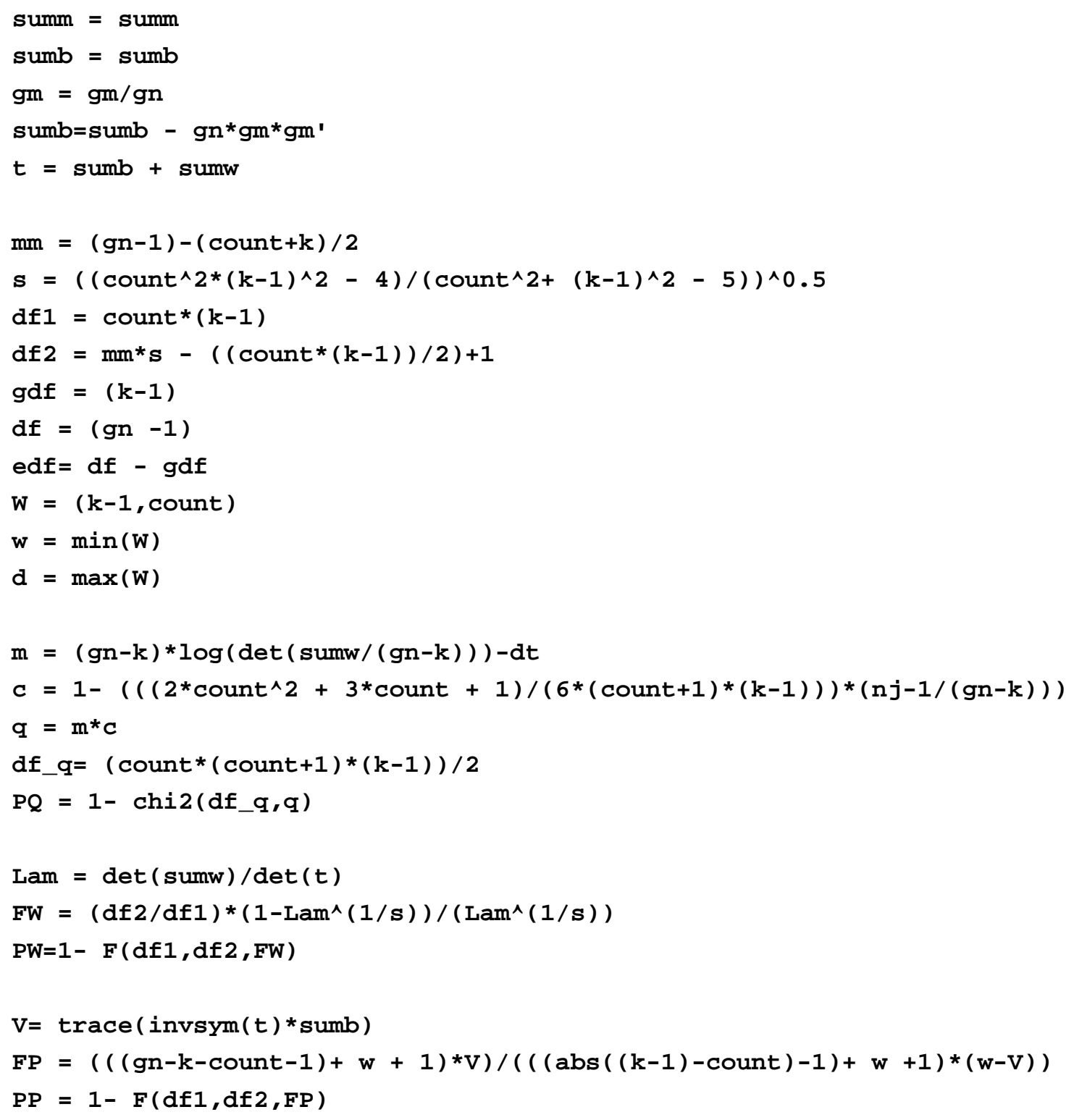




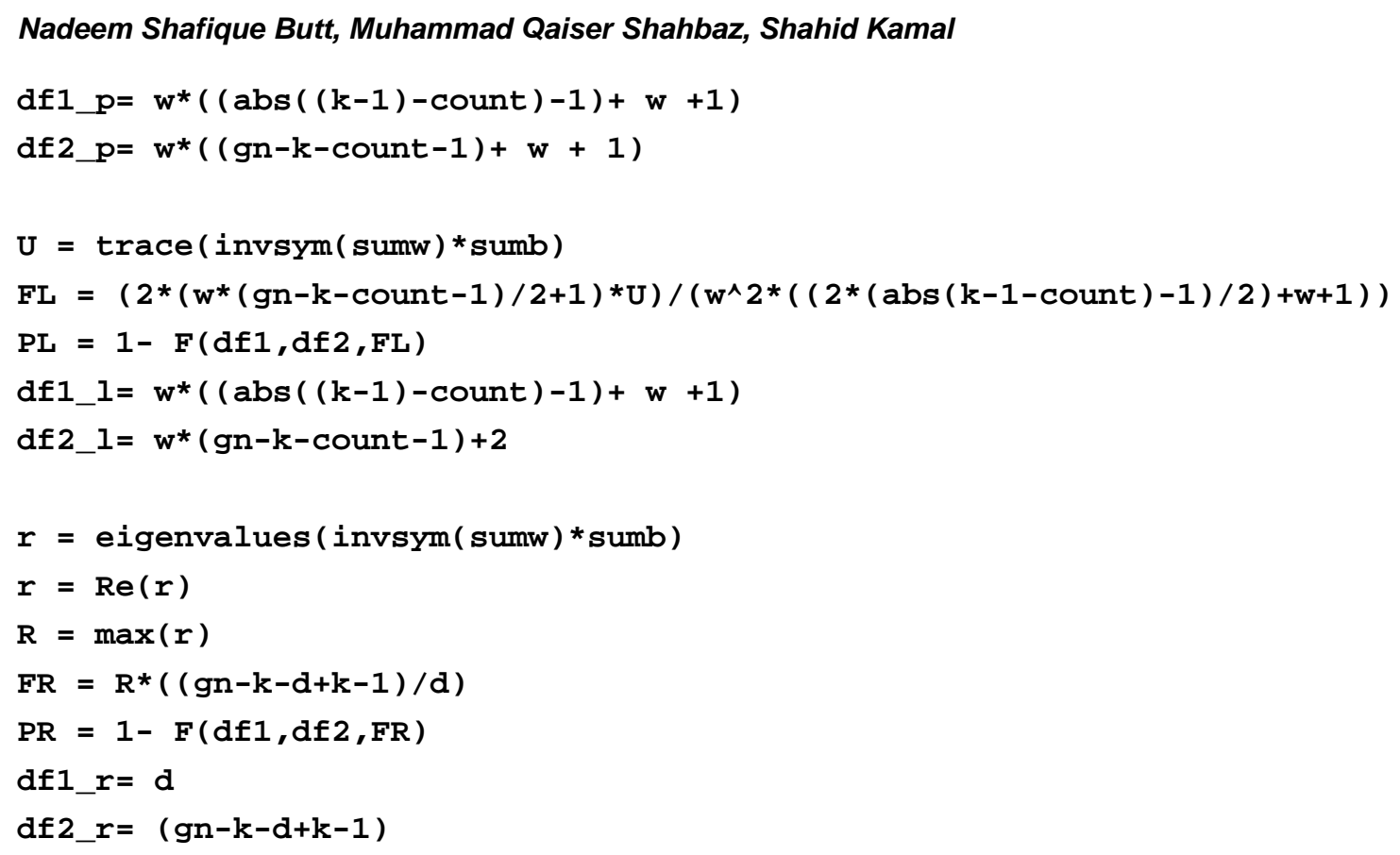

end

\section{Numerical Example}

In this section we have given a hypothetical example to demonstrate the usefulness of the program that can be used to perform MANOVA on summary statistics.

\section{Example}

In particular, the telecommunication company has separated the monthly bill into amounts spent on Long distance, Toll free, Equipment, Calling card, and Wireless services, and categorized the customers based upon countries (India, China, Malaysia) and apply MANOVA test to see is there significant difference in monthly billings of these three countries. Suppose the results are published in a report along with summary statistics. Now suppose you wish to compare how monthly billings in Pakistan are different from these three countries.

You can have raw data for Pakistan but may not have raw data for other three countries. In such situation our program manovai can be used to perform MANOVA. 


\section{Table 4.1: Summary data that obtained from published report and calculated from Pakistani sample}

\begin{tabular}{|c|c|c|c|c|c|c|c|c|c|}
\hline \multirow[b]{2}{*}{ Country } & & \multirow[b]{2}{*}{$\mathbf{N}$} & \multirow[b]{2}{*}{ Mean } & \multicolumn{5}{|c|}{ Variance - Covariance } & \\
\hline & & & & V1 & V2 & V3 & V4 & V5 & \\
\hline \multirow{5}{*}{ India } & $\begin{array}{l}\text { Long Distance } \\
\text { last month }\end{array}$ & 322 & 11.9 & 117.3 & 29.1 & -9.3 & 58.8 & 9.5 & \multirow{20}{*}{ 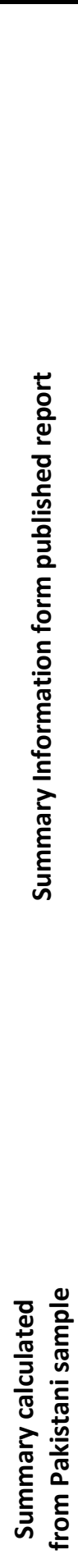 } \\
\hline & $\begin{array}{l}\text { Toll free last } \\
\text { month }\end{array}$ & 322 & 12.5 & 29.1 & 233.4 & 5.3 & 75.7 & 125.3 & \\
\hline & $\begin{array}{l}\text { Equipment last } \\
\text { month }\end{array}$ & 322 & 14.7 & -9.3 & 5.3 & 369.3 & -5.4 & 204.2 & \\
\hline & $\begin{array}{l}\text { Calling card last } \\
\text { month }\end{array}$ & 322 & 14.1 & 58.8 & 75.7 & -5.4 & 191.4 & 47.9 & \\
\hline & $\begin{array}{l}\text { Wireless last } \\
\text { month }\end{array}$ & 322 & 11.1 & 9.5 & 125.3 & 204.2 & 47.9 & 370.2 & \\
\hline \multirow{5}{*}{ China } & $\begin{array}{l}\text { Long Distance } \\
\text { last month }\end{array}$ & 334 & 11.3 & 96.5 & 55.9 & -17.3 & 49.7 & 17.0 & \\
\hline & $\begin{array}{l}\text { Toll free last } \\
\text { month }\end{array}$ & 334 & 13.5 & 55.9 & 285.6 & 37.6 & 79.7 & 163.3 & \\
\hline & $\begin{array}{l}\text { Equipment last } \\
\text { month }\end{array}$ & 334 & 14.0 & -17.3 & 37.6 & 360.0 & 33.4 & 219.8 & \\
\hline & $\begin{array}{l}\text { Calling card last } \\
\text { month }\end{array}$ & 334 & 13.3 & 49.7 & 79.7 & 33.4 & 187.7 & 88.0 & \\
\hline & $\begin{array}{l}\text { Wireless last } \\
\text { month }\end{array}$ & 334 & 12.2 & 17.0 & 163.3 & 219.8 & 88.0 & 382.0 & \\
\hline \multirow{5}{*}{ Malaysia } & $\begin{array}{l}\text { Long Distance } \\
\text { last month }\end{array}$ & 344 & 11.9 & 109.1 & 23.5 & -2.1 & 64.4 & 13.0 & \\
\hline & $\begin{array}{l}\text { Toll free last } \\
\text { month }\end{array}$ & 344 & 13.8 & 23.5 & 335.6 & 9.5 & 79.8 & 156.8 & \\
\hline & $\begin{array}{l}\text { Equipment last } \\
\text { month }\end{array}$ & 344 & 14.0 & -2.5 & 9.5 & 363.7 & 1.5 & 210.4 & \\
\hline & $\begin{array}{l}\text { Calling card last } \\
\text { month }\end{array}$ & 344 & 13.9 & 64.3 & 79.8 & 1.5 & 216.0 & 75.9 & \\
\hline & $\begin{array}{l}\text { Wireless last } \\
\text { month }\end{array}$ & 344 & 11.5 & 13.0 & 156.8 & 210.4 & 75.9 & 414.6 & \\
\hline \multirow{5}{*}{ Pakistan } & $\begin{array}{l}\text { Long Distance } \\
\text { last month }\end{array}$ & 500 & 10.0 & 8.7 & 7.7 & -3.4 & 7.9 & 1.4 & \\
\hline & $\begin{array}{l}\text { Toll free last } \\
\text { month }\end{array}$ & 500 & 12.7 & 7.7 & 240.3 & 37.7 & 69.4 & 159.5 & \\
\hline & $\begin{array}{l}\text { Equipment last } \\
\text { month }\end{array}$ & 500 & 13.9 & -3.4 & 37.7 & 365.0 & 24.3 & 243.9 & \\
\hline & $\begin{array}{l}\text { Calling card last } \\
\text { month }\end{array}$ & 500 & 12.9 & 7.9 & 69.4 & 24.3 & 143.0 & 82.6 & \\
\hline & $\begin{array}{l}\text { Wireless last } \\
\text { month }\end{array}$ & 500 & 11.1 & 1.4 & 159.5 & 243.9 & 82.6 & 410.9 & \\
\hline
\end{tabular}


Table given in table 4.1 can be entered directed into Stata data editor in the following manner

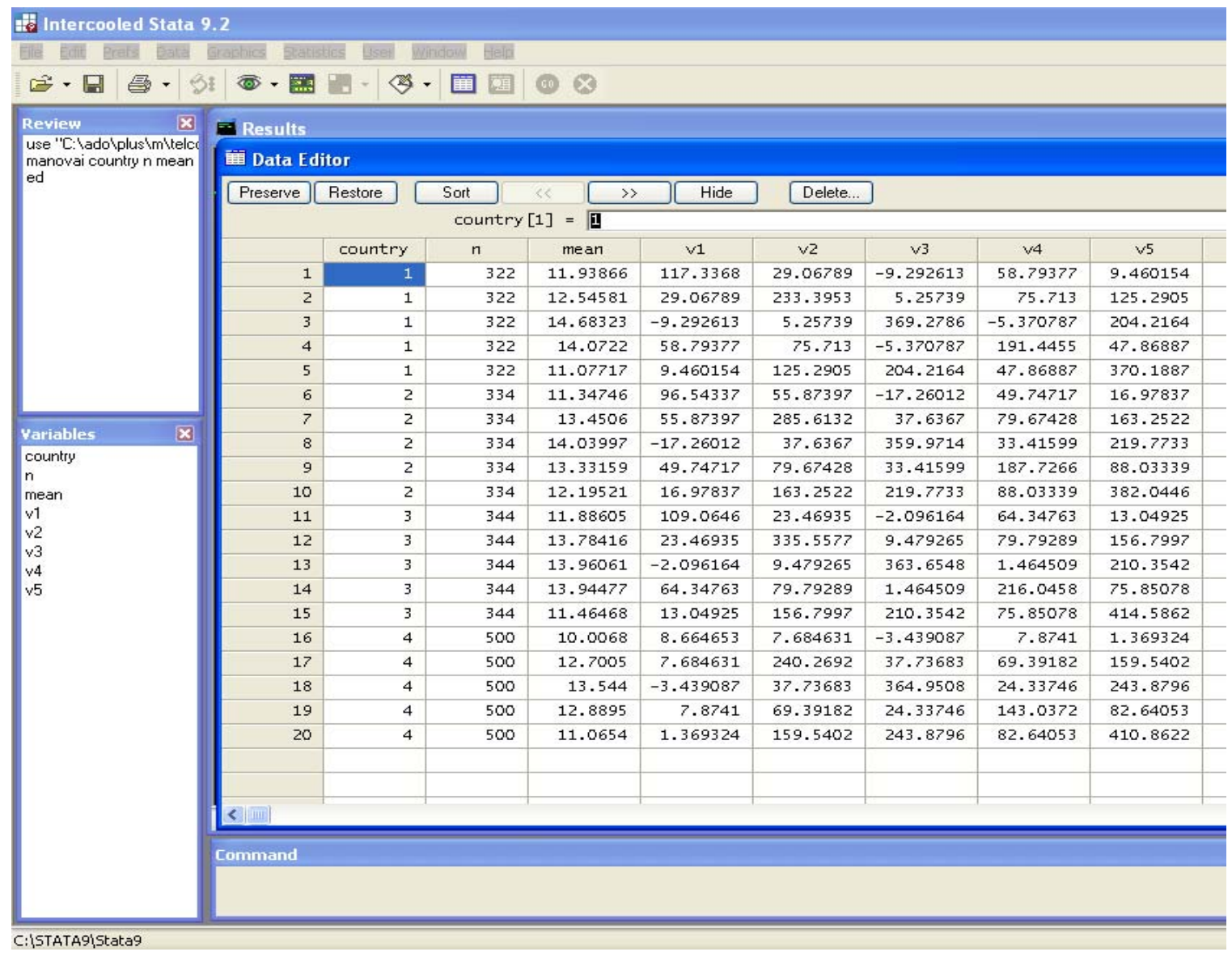

Following out can be obtained after using "manovai" command

- manovai country n mean v1-v5

Number of obs $=1500$

W $=$ Wilks' lambda

$I=$ Lawley-Hotelling trace

$P=$ Pillai's trace

$\mathrm{R}=$ Roy's largest root

\begin{tabular}{|c|c|c|c|c|c|c|c|}
\hline Source & & tatistic & df & F (df1 & df2) & $\mathbf{F}$ & prob $>$ F \\
\hline \multirow[t]{4}{*}{ Group } & W & 0.9879 & 3 & 15.0 & 4119.2 & 1.21 & 0.2540 \\
\hline & $\mathbf{P}$ & 0.0121 & & 15.0 & 4482.0 & 1.21 & 0.2552 \\
\hline & I & 0.0122 & & 15.0 & 4472.0 & 1.21 & 0.2530 \\
\hline & $\mathbf{R}$ & 0.0102 & & 5.0 & 1494.0 & 3.05 & 0.0001 \\
\hline
\end{tabular}

$\begin{array}{ll}\text { Residual } & 1496 \\ \text { Total } & 1499\end{array}$

Test of Homogeneity of Covariance Matrices

Chi-Sq $=794.097 \quad$ df $=45 \quad P=0.0000$ 


\section{References}

1. Box, G. E. P. (1949). A general distribution theory for a class of likelihood ratio criteria, Biometrike, 36, 317 - 346.

2. Butt, N. S., Kamal, S., Shahbaz, M. Q. (2006). "ANOVA using summary data: A STATA programe" Pak Jour. Of Stat. and Oper. Res. Vol. 2(1).

3. Hotelling, H. (1951). A generalized T test and measure of multivariate dispersion, Proceeding of the Second Berkeley Symposium on Mathematical Statistics and Probability, University of California, Los Angeles and Berkeley, $23-41$.

4. Pillai, K. C. S. (1955). Some new test criteria in multivariate analysis, Annals of Mathematical Statistics, 26, 117 - 121.

5. Roy, S. N. (1953). On a heuristic method of test construction and its use in multivariate analysis, Annals of Mathematical Statistics, 24, 220 - 238.

6. Wilks, S. S. (1932). Certain generalizations in the analysis of variance, Biometrika, 24, $471-494$. 